\title{
COVID-19: Thick Pus, Mucus and Sputum with Streaks of Blood as a Cause of Airway Obturation in SARS and Oxygen-Foaming Pus Solvent as a Medicine for their Recanalization
}

\section{Aleksandr L Urakov ${ }^{1 *}$, Ilnur I Yagudin ${ }^{2}$, Daria 0 Suntsova², Milena D Svetova $^{2}$ and Anastasia P Stolyarenko ${ }^{2}$}

${ }^{1}$ Professor, Head of the Department of General and Clinical Pharmacology, Izhevsk State Medical Academy, Izhevsk, Russia and Leader Researcher, Institute of

Mechanics, Udmurt Federal Research Center, Ural Branch of the Russian Academy of Sciences, Izhevsk, Russia

${ }^{2}$ Student, Izhevsk State Medical Academy, Izhevsk, Russia

*Corresponding Author: Aleksandr L Urakov, Professor, Head of the Department of General and Clinical Pharmacology, Izhevsk State Medical Academy, Izhevsk, Russia.
Received: April 27, 2021

Published: April 28, 2021

(C) All rights are reserved by Aleksandr L

Urakov., et al.
A few years ago, "pus solvents drugs" were discovered in Russia [1]. These drugs are antiseptics and are alkaline solutions of hydrogen peroxide [2]. As solvents of thick purulent masses, it was proposed to use aqueous solutions of $0.3-3 \%$ hydrogen peroxide and $1-10 \%$ sodium bicarbonate. They were originally proposed for the treatment of purulent diseases. The peculiarity of their use in medicine is that they are intended exclusively for topical use. And there is one more feature: before using them, they are heated to a temperature of $+42-+45^{\circ} \mathrm{C}$. The mechanism of action of these drugs is that when they interact locally with pus, these drugs cause an alkaline saponification of the protein-lipid complexes in it. At the same time, the enzyme catalase (which is always present in pus) decomposes hydrogen peroxide into oxygen gas and water, which provides the formation of oxygen gas bubbles. This is how the cold boiling process begins. Pus solvents have been shown to provide and dissolve not only thick pus, but also blood clots, plaque, sulfur plugs, and tear stones [2,3].

Up until 2020, pus solvents were not offered for airway sanitation in obturation bronchitis, which complicates non-specific pneumonia caused by COVID-19. However, SARS caused by COVID-19 is often triggered by concomitant bacteria, which can cause not only acute lung damage, but also the accumulation of mucus and pus in the respiratory tract [4].

At the same time, even forced artificial ventilation of the lungs does not ensure the movement of air and oxygen gas through the respiratory tract to the alveoli of the lungs. This causes suffocation, hypoxia, and death from hypoxic damage to brain cells. Death occurs despite maximum contractions and relaxation of the diaphragm and chest muscles and/or intensive forced ventilation of the lungs [5]. Today, it is believed that in such cases, oxygen saturation of the blood is possible only due to extrapulmonary respiration [6]. Extracorporeal membrane oxygenation is used for this purpose all over the world [7]. However, the mortality rate from extracorporeal membrane oxygenation in respiratory failure can often exceed $50 \%$. In addition, extracorporeal membrane oxygenation costs from $\$ 5,000$ to $\$ 10,000$ per day [8]. At the same time, to save lives in severe SARS, it is often necessary to apply ECMO for more than a week in a row.

It is shown that the generally accepted standard of complex therapy of patients with nonspecific pneumonia does not contain antiseptics that dissolve pus (pus solvents) [9]. In Russia, it was shown for the first time that to save the lives of patients with nonspecific pneumonia complicated by obstructive purulent bronchitis, there is no alternative to the local use of drugs that dissolve thick mucus and thick pus with the help of solvents of thick purulent masses. This is the only way to urgently improve blood oxygenation during lung ventilation [4]. Therefore, in Russia, it was suggested that pus solvents may well act as expectorants in obstructive bronchitis. In order to treat obstructive bronchitis, it was proposed to use pus solvents in the form of an aerosol for inhalation administration. So

Citation: Aleksandr L Urakov., et al. "COVID-19: Thick Pus, Mucus and Sputum with Streaks of Blood as a Cause of Airway Obturation in SARS and Oxygen-Foaming Pus Solvent as a Medicine for their Recanalization". Acta Scientific Women's Health 3.5 (2021): 75-77. 
in the fall of 2020, an aerosol for inhalation in obstructive bronchitis was patented in Russia (Patent RU 2735502).

This aerosol is prepared from a solution of $1-2 \%$ sodium bicarbonate and $0.3-0.5 \%$ hydrogen peroxide. The aerosol has microparticles of 0.5 - 2 microns in size and is administered by inhalation at a temperature of $+41-+55^{\circ} \mathrm{C}$. In addition to hydrogen peroxide and sodium bicarbonate, the solution may contain $0.5 \%$ lidocaine hydrochloride [10].

It is shown that when inhaled, aerosol microparticles quickly penetrate deep into the respiratory tract, settle on the surface of pus and mucus, quickly destroy and dissolve them due to thermal alkaline saponification and oxygen foaming. In this case, the biological masses are loosened by the release of oxygen gas bubbles, which is formed as a result of the catalase cleavage of hydrogen peroxide. The fact is that pus and blood contain the enzyme catalase. Very important is the high temperature of the aerosol, since local hyperthermia is necessary for maximum acceleration of the rate of chemical and physico-chemical processes in the interaction of aerosol microparticles with protein and protein-lipid complexes of pus and mucus according to the Arrhenius law. It was shown that such an aerosol, a few seconds after the start of inhalation, almost completely loosens and dissolves the thick pus and thick mucus in the lower bronchi, quickly promotes expectoration of sputum, after which the suffocation disappears for several hours.

Then, in February 2021, the first patent for "Aerosol for invasive mechanical ventilation in COVID-19" was issued in Russia (Patent RU 2742505). The main ingredients of this aerosol are also sodium bicarbonate and hydrogen peroxide. The aerosol is prepared from a solution at a pH of 8.5 and an osmotic activity of 370 - 1990 mosmol/l of water. The aerosol is proposed to be used for inhalation warm at a temperature of $+37-+55^{\circ} \mathrm{C}$.

It was shown that the first resuscitation aerosol provides urgent dissolution of thick pus and thick mucus in the respiratory tract, an increase in oxygen content, elimination of mucosal edema, improvement of airway patency for respiratory gases in obstructive bronchitis, and increased blood oxygenation during artificial lung ventilation in resuscitation patients. An important advantage of the first resuscitation aerosol is that it increases the oxygenation of the lungs and blood due to molecular oxygen formed from hydro- gen peroxide under the influence of catalase, which is very much in pus and in red blood cells.

In addition, it has been shown that an aerosol of hydrogen peroxide and sodium bicarbonate improves expectoration of sputum, mucus and pus, facilitates lung ventilation and breathing, expands the lumen of the bronchi without local irritating effects, without increasing the symptoms of obstructive bronchitis, without pneumonia and bronchospasm.

\section{Conclusion}

A new coronavirus infection causes bilateral SARS. Severe SARS is often complicated by obstructive bronchitis due to the fact that mucus and pus are released into the lumen of the respiratory tract. As a result, it is difficult to ventilate the lungs, which leads to hypoxia. To save the lives of resuscitation patients, artificial lung ventilation is used, which does not always increase the oxygenation of the lungs and blood due to the obstruction of the respiratory tract with mucus and pus. However, the standard of drug therapy does not yet include drugs-solvents of mucus and pus, which were recently discovered in Russia. In particular, special aerosols invented in this country, the main ingredients of which are hydrogen peroxide and sodium bicarbonate, and which in 2020 and 2021 were first proposed for the inhaled treatment of obstructive bronchitis and severe SARS. It has been shown that the inhalation application of an aerosol of pus solvents very quickly eliminates hypoxia caused by blockage of the respiratory tract with pus and mucus.

These results show that in Russia, the right path has been found for a promising targeted search and development of resuscitation drugs and methods of their inhaled and/or intra-pulmonary use for emergency life-saving of patients suffering from a severe stage of suffocation in non-specific pneumonia caused by COVID-19.

\section{Bibliography}

1. Urakov AL. "Pus solvents as new drugs with unique physical and chemical property". Reviews on Clinical Pharmacology and Drug Therapy 17.4 (2019): 89-95.

2. Urakov A., et al. "Oxygen alkaline dental's cleaners from tooth plaque, food debris, stains of blood and pus: A narrative review of the history of inventions". Journal of International Society of Preventive and Community Dentistry 9.5 (2019): 427-433. 
3. Urakov AL., et al. "Medications for dissolving thick mucus and pus in the respiratory, vision and hearing organs". Journal of Bio Innovation 9.6 (2020): 1212-1218.

4. Urakov AL and Urakova NA. "COVID-19: Optimization of respiratory biomechanics by aerosol pus solvent”. Russian Journal of Biomechanics 25.1 (2021): 86-90.

5. Wunsch H. "Mechanical ventilation in COVID-19: interpreting the current epidemiology". American Journal of Respiratory and Critical Care Medicine 202.1 (2020): 1-4.

6. Urakov AL. "COVID-19: Original simple and cheap extrapulmonary oxygenation as an alternative to ECMO". Journal of Bio Innovation 9.4 (2020): 648-654.

7. Pappalardo F and Crivellari M. "Predicting outcome of venovenous ECMO: look outside the lung!". Journal of Thoracic Disease 10.3 (2018): 1356-1360.

8. Harvey MJ., et al. "U.S. and international in-hospital costs of extracorporeal membrane oxygenation: a systematic review". Applied Health Economics and Health Policy 13.4 (2015): 341357.

9. Urakov AL and Urakova NA. "COVID-19: What drug can be used to treat a new coronavirus disease and why". Journal of Bio Innovation 9.3 (2020): 241-251.

10. Urakov A and Urakova N. "COVID-19. Cause of death and medications". International Journal of Comprehensive and Advanced Pharmacology 5.2 (2020): 45-48.

\section{Assets from publication with us}

- Prompt Acknowledgement after receiving the article

- Thorough Double blinded peer review

- Rapid Publication

- Issue of Publication Certificate

- High visibility of your Published work

Website: www.actascientific.com/

Submit Article: www.actascientific.com/submission.php Email us: editor@actascientific.com

Contact us: +919182824667

Citation: Aleksandr L Urakov., et al. "COVID-19: Thick Pus, Mucus and Sputum with Streaks of Blood as a Cause of Airway Obturation in SARS and Oxygen-Foaming Pus Solvent as a Medicine for their Recanalization". Acta Scientific Women's Health 3.5 (2021): 75-77. 